\title{
Produção de serapilheira em três trechos de uma floresta semidecídua com diferentes graus de perturbação na Estação Ecológica do Tripuí, Ouro Preto, MG
}

\author{
MÁRCIO DE SOUZA WERNECK ${ }^{1}$, GILBERTO PEDRALLI ${ }^{2,3}$ \\ e LETÍCIA FARAH GIESEKE ${ }^{2}$
}

(recebido: 28 de junho de 2000; aceito: 14 de fevereiro de 2001)

\begin{abstract}
Litterfall in three sites of semideciduous forest with different disturbance degree in the Tripuí Ecological Station, Ouro Preto, MG). Three sites of semideciduous mesophytic forest were studied in the Tripuí Ecological Station aiming to verifying the litterfall differences according to the site disturbance degree. Samples were collected from July 1997 to August 1998, using ten $0.36 \mathrm{~m}^{2}$ traps in each site. Litterfall in sites A1 $\left(6.78 \pm 0.65 \mathrm{t}^{-h^{-1}} \cdot \mathrm{y}^{-1}\right)$ and A2 $\left(6.58 \pm 0.49 \mathrm{t}_{\mathrm{h}} \mathrm{h}^{-1} \cdot \mathrm{y}^{-1}\right)$ were significantly different from that observed in site A3 $\left(5.09 \pm 0.58 \mathrm{t}^{-h^{-1}} \cdot \mathrm{y}^{-1}\right)$ (ANOVA, $\mathrm{p}<0.01$ ). The three sites presented similar patterns of litterfall with peaking in september (Tukey test, $\mathrm{p}<0.0001$ ). The abundance of pioneer species was less important than stature of canopy in litterfall production in each site.

RESUMO - (Produção de serapilheira em três trechos de floresta semidecídua com diferentes graus de perturbação na Estação Ecológica do Tripuí, Ouro Preto, MG). Foram estudados três trechos de uma floresta semidecídua na Estação Ecológica do Tripuí com o objetivo de verificar a ocorrência de diferenças na produção de serapilheira de acordo com o grau de perturbação. A serapilheira foi coletada entre julho de 1997 e agosto de 1998, usando-se dez coletores de $0,36 \mathrm{~m}^{2}$, em cada trecho. A produção anual nos trechos A1 $\left(6,78 \pm 0,65\right.$ t.ha $\left.^{-1}\right)$ e A2 $\left(6,58 \pm 0,49\right.$ t.ha $\left.^{-1}\right)$ foi significativamente superior à estimada no trecho A3 $\left(5,09 \pm 0,58\right.$ t.ha $\left.^{-1}\right)$ (ANOVA, $\mathrm{p}<0,01)$. Os três trechos apresentaram padrão semelhante de produção da serapilheira, com o pico máximo ocorrendo em setembro (teste Tukey, $\mathrm{p}<0,0001$ ). A abundância de espécies pioneiras foi menos importante que a estatura do dossel na determinação da produção de serapilheira nas três áreas.
\end{abstract}

Key words - Litterfall, disturbance, semideciduous forest, Tripuí Ecological Station

\section{Introdução}

Os ecossistemas de florestas tropicais, via de regra, apresentam produção contínua de serapilheira no decorrer do ano, sendo que a quantidade produzida nas diferentes épocas depende do tipo de vegetação considerado (Leitão-Filho et al. 1993). Dentro de um mesmo tipo florestal, a produção também varia de acordo com o grau de perturbação (Delitti 1989, Pagano 1989). Áreas mais perturbadas apresentam um número muito elevado de espécies pioneiras que têm um crescimento rápido, ciclo de vida mais curto, investindo pesadamente na produção de biomassa em um curto espaço de tempo (Martins \& Rodrigues 1999). Por outro lado, as áreas menos perturbadas possuem um pequeno número de espécies pioneiras, apresentando menor produção

1. Universidade Federal de Minas Gerais, Departamento de Botânica, Caixa Postal 486, 30161-970 Belo Horizonte, MG, Brasil.

2. Fundação Centro Tecnológico de Minas Gerais, Setor de Recursos da Terra, Av. José Cândido da Silveira, 2000, 31170-000 Belo Horizonte, MG, Brasil.

3. Autor para correspondência: pedralli@cetec.br líquida de biomassa (Leitão-Filho et al. 1993). Desta forma, diferenças na produção de serapilheira entre trechos próximos podem estar relacionadas aos diferentes graus de perturbação que são encontrados dentro de um mesmo tipo florestal.

No Brasil, vários dos estudos sobre produção de serapilheira em ecossistemas de floresta mesófila semidecídua foram realizados no Estado de São Paulo (Meguro et al. 1979, Pagano 1989, Morellato 1992, Cesar 1993, Schlittler et al. 1993). Esses ecossistemas foram, em sua grande maioria, transformados em agroecossistemas, tornando indispensáveis os estudos das áreas remanescentes, onde ainda ocorra esse tipo de vegetação.

Este trabalho teve por objetivos estudar a relação entre a produção de serapilheira e a estrutura da vegetação de três trechos de uma floresta mesófila semidecídua, na Estação Ecológica do Tripuí, município de Ouro Preto (MG). Especificamente, objetivou-se averiguar se trechos estruturalmente distintos apresentam produção total anual de serapilheira diferenciada e verificar se os três trechos da floresta semidecídua apresentam padrão semelhante de produção de serapilheira ao longo do período de estudo. 


\section{Material e métodos}

A Estação Ecológica do Tripuí (E.E. Tripuí), situa-se no

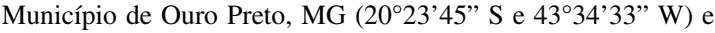
possui uma área de 337 ha, com níveis altimétricos variando entre 1280 e $1450 \mathrm{~m}$. Os solos são litólicos, de natureza álica e textura areno-siltosa. O clima é do tipo Cwb pela classificação de Köppen, subtropical moderado úmido, com precipitações abundantes no verão (média anual de $1.600 \mathrm{~mm}$ ) e temperaturas frias, com uma média anual de $18^{\circ} \mathrm{C}$ (Werneck et al. 2000).

Foram selecionados três trechos da floresta semidecídua da E.E. Tripuí que representassem as diferentes fisionomias dentro da floresta. A amostragem para a análise estrutural destes trechos foi descrita por Werneck et al. (2000). A tabela 1 resume as principais características estruturais observadas nos três trechos estudados. A área 1 "Repolheiro" (A1) representa o trecho mais preservado da floresta, não havendo relatos de perturbação, como a retirada de madeira, para os últimos trinta anos. A área 3 "Chá" (A3) representa o trecho sucessional mais jovem da floresta e corresponde a uma antiga plantação de chá preto (Camellia sinensis (L.) Kuntze), abandonada há pelo menos quarenta anos. A área 2 "Macacos" (A2) apresenta uma fisionomia intermediária entre os trechos A1 e A3, não havendo relatos de perturbação nos últimos trinta anos.

Para a obtenção de dados de produção de serapilheira, utilizaram-se 10 coletores de madeira $0,36 \mathrm{~m}^{2}$, distribuídos de forma aleatória no interior de cada trecho. O material produzido foi coletado a cada 2,5 meses, durante o período de 15 de julho de 97 a 30 de agosto de 98 . O material foi triado manualmente nas frações folhas e demais partes. Cada fração foi submetida a secagem a $80^{\circ} \mathrm{C}$ e, após atingir peso constante, foi medido o seu peso seco.

Para testar a ocorrência de diferenças na produção anual entre os três trechos utilizou-se a Análise de Variância (ANOVA), seguida do teste de Tukey. Para cada trecho amostral, comparou-se a produção nos meses de coleta através dos mesmos testes, tendo por objetivo verificar a existência de picos na produção ao longo do período de estudo. Os testes estatísticos foram realizados de acordo com Zar (1999), sendo apresentadas as médias \pm erro padrão.

\section{Resultados e Discussão}

A maior produção anual de serapilheira foi estimada para o trecho A1 $\left(6,78 \pm 0,65\right.$ t.ha $\left.^{-1}\right)$, seguida do trecho A2 $\left(6,58 \pm 0,49\right.$ t.ha $\left.^{-1}\right)$ e por fim o trecho A3 $\left(5,09 \pm 0,58\right.$ t.ha $\left.{ }^{-1}\right)$. Cabe ressaltar que é esperado um erro subestimando o valor real da produção anual de serapilheira, devido ao tempo de exposição à decomposição (Ewel 1976), o que pode prejudicar a comparação com outros estudos. Por outro lado, os dados se revelam interessantes em relação à comparação da produção entre trechos com diferentes graus de perturbação. A análise de variância identificou diferenças significativas na produção anual entre os três trechos (ANOVA;
$\mathrm{F}=6,16 ; \mathrm{p}<0,01)$, sendo que A3 teve produção significativamente inferior aos trechos A1 e A2 (teste Tukey; $\mathrm{p}<0,05$ ), não sendo observada diferença significativa entre estes dois últimos trechos (teste Tukey; p > 0,05). Embora trechos mais perturbados tenham um maior número de espécies pioneiras (Ewel 1976), como observado no presente estudo, a produção nesses trechos também poderia estar relacionada à proporção ocupada pelas copas. Parece que as alturas e os diâmetros das árvores refletem-se no espaço horizontal ocupado pelos diâmetros das copas e, neste caso, ocorrem progressões geométricas, de modo que quanto maiores forem as árvores, bem maiores serão as proporções ocupadas pelas copas (Schlittler et al. 1993). Os trechos A1 e A2 tiveram um volume de madeira significativamente superior ao trecho A3 (tabela 1), como reflexo da maior abundância de indivíduos com DAP $\geq 10 \mathrm{~cm}$ e da presença de um dossel mais desenvolvido. Schlittler et al. (1993) também verificaram que a produção de serapilheira era superior nos trechos com maior volume de madeira e que tiveram um dossel maior, em uma floresta semidecídua no Pontal do Paranapanema (SP). Moraes et al. (1999) estudaram uma porção de floresta atlântica e de floresta de restinga na Ilha do Cardoso (SP) e verificaram menor produção na floresta de restinga, onde o volume de madeira era inferior, como reflexo da menor abundância de indivíduos por hectare com DAP $\geq 8 \mathrm{~cm}$, e um dossel

Tabela 1. Características estruturais dos três trechos (A1, A2 e A3) de uma floresta semidecídua na E.E. Tripuí, Ouro Preto, MG. Letras diferentes, para cada característica entre os trechos, indicam diferenças significativas ao nível de 5\% pelo teste do Qui-quadrado.

\begin{tabular}{|c|c|c|c|}
\hline Características & $\mathrm{A} 1$ & $\mathrm{~A} 2$ & A3 \\
\hline Densidade (ind. ha $\left.{ }^{-1}\right)^{*}$ & $4167 \mathrm{a}$ & $5167 \mathrm{ab}$ & $7200 \mathrm{~b}$ \\
\hline Volume de madeira $\left(\mathrm{m}^{3}\right)$ & $11,5 \mathrm{a}$ & $10,5 \mathrm{a}$ & $5,8 \mathrm{~b}$ \\
\hline $\begin{array}{l}\text { Percentual de indivíduos } \\
\text { com DAP }<5 \mathrm{~cm}^{*}\end{array}$ & $52,6 \mathrm{a}$ & $60,0 \mathrm{a}$ & $70,9 b$ \\
\hline $\begin{array}{l}\text { Percentual de indivíduos } \\
\text { com DAP } \geq 10 \mathrm{~cm}^{*}\end{array}$ & $20,0 \mathrm{a}$ & $17,1 \mathrm{a}$ & $6,3 b$ \\
\hline $\begin{array}{l}\text { Abundância relativa de } \\
\text { pioneiras }(\%)\end{array}$ & $5,6 \mathrm{a}$ & $7,7 \mathrm{a}$ & $16,7 \mathrm{~b}$ \\
\hline $\begin{array}{l}\text { Área basal relativa de } \\
\text { pioneiras }(\%)\end{array}$ & $11,0 \mathrm{a}$ & $26,7 b$ & $47,7 \mathrm{c}$ \\
\hline
\end{tabular}

*Werneck et al. (2000). 
mais baixo. Assim, a abundância de espécies pioneiras pode ser menos importante que o tamanho e o porte do dossel na determinação da produção da serapilheira (Songwe et al. 1988). Por outro lado, Leitão-Filho et al. (1993) julgaram que a grande abundância de pioneiras foi preponderante para a maior produção de serapilheira nos trechos sucessionais iniciais em um trecho de floresta atlântica em Cubatão (SP).

A fração foliar representou a maior parte do material coletado, encontrando-se $77,7 \%$ no trecho A1, $72,1 \%$ no trecho A2 e 79,3\% no trecho A3, conferindo com os resultados de Herbohn \& Congdon (1993), que encontraram o maior percentual de folhas $(76 \%)$ em áreas mais perturbadas por corte seletivo em uma floresta na Austrália, e com os de Leitão-Filho et al. (1993), que estimaram nos trechos mais perturbados de floresta atlântica em Cubatão (SP) uma fração foliar superior a 81\%. Martins \& Rodrigues (1999) observaram maior participação foliar (76\%) em clareiras de uma floresta semidecídua em Campinas (SP). A elevada deposição de folhas em florestas que apresentam distúrbios, deve-se ao rápido crescimento e renovação foliar das espécies pioneiras, canalizando os fotoassimilados em um primeiro momento à produção vegetativa (Martins \& Rodrigues 1999).

As três áreas apresentaram padrão semelhante de produção da serapilheira, com o pico máximo de produção ocorrendo em setembro (figura 1). Esse mês foi significativamente diferente dos outros meses de coleta (teste Tukey; $\mathrm{p}<0,0001$ ) e coincide com o final do período seco e o início do período chuvoso, onde a caducifolia se faz presente em

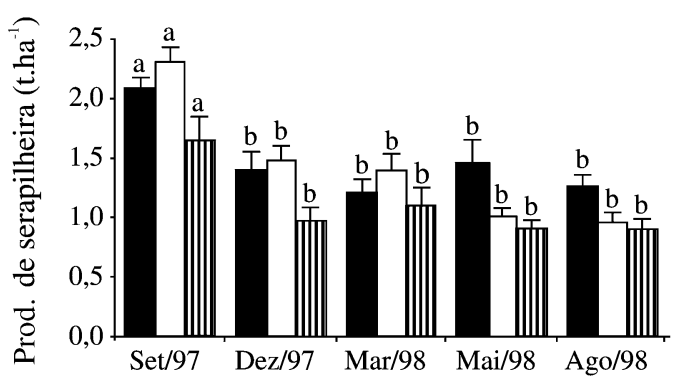

Figura 1. Produção de serapilheira nos meses de coleta, nos

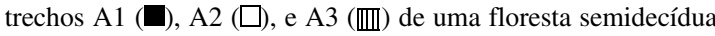
na E.E. Tripuí. As barras indicam o erro-padrão. As diferenças significativas na produção entre os meses de coleta (teste Tukey, $\mathrm{p}<0,0001)$ são indicadas por letras diferentes. resposta à sazonalidade climática verificada em áreas de floresta semidecídua (Leitão-Filho 1982). A maior produção de serapilheira em setembro está de acordo com o observado em outras florestas semidecíduas do sudeste (Schlittler et al. 1993, Cesar 1993, Dias \& Oliveira-Filho 1997). Nas florestas tropicais estacionais, é esperada maior produção de serapilheira no final do período seco, ocasionada pelo déficit hídrico observado nesta época (Cesar 1993).

Os resultados obtidos no presente trabalho sugerem que as diferenças quantitativas observadas na produção da serapilheira entre os três trechos estudados podem estar relacionadas aos diferentes graus de perturbação que a floresta semidecídua da E.E. Tripuí sofreu no passado. Na E.E. Tripuí a maior produção não está condicionada à presença de pioneiras que são encontradas em abundância nos trechos mais perturbados, e sim, à estrutura da floresta (tabela 1) e à conseqüente formação de um dossel mais desenvolvido.

Agradecimentos - À FAPEMIG, pelo financiamento do projeto e bolsas de Aperfeiçoamento para o primeiro autor e de Iniciação Científica para a terceira autora; ao José Carlos do Santos (SAT/CETEC), pela ajuda nos trabalhos de campo e ao Instituto Estadual de Florestas - IEF, na pessoa do Biólogo José Aristides Salgado Neto, gerente da Estação Ecológica do Tripuí, e demais funcionários, pelo apoio irrestrito em todas as etapas do projeto; ao Sérvio Pontes Ribeiro, pelo auxílio nas análises estatísticas.

\section{Referências bibliográficas}

CESAR, O. 1993. Produção de serapilheira na mata mesófila semidecídua da Fazenda Barreiro Rico, Município de Anhembi, SP. Revista Brasileira de Biologia 53:671-681.

DELITTI, W.B.C. 1989. Ciclagem de nutrientes minerais em matas ciliares. In Simpósio sobre Mata Ciliar (L.M. Barbosa, coord.). Fundação Cargill, Campinas, p.88-98.

DIAS, H.C.T. \& OLIVEIRA-FILHO, A.T. 1997. Variação temporal e espacial da produção de serapilheira em uma área de floresta estacional semidecídua montana em Lavras-MG. Revista Árvore 21:11-26.

EWEL, J.J. 1976. Litter fall and leaf decomposition in a tropical forest succession in eastern Guatemala. Journal of Ecology 64:293-308.

HERBOHN, J.L. \& CONGDON, R.A. 1993. Ecosystem dynamics at disturbed and undisturbed sites in north Queensland wet tropical rain forest. II. Litterfall. Journal of Tropical Ecology 9:365-380.

LEITÃO-FILHO, H.F. 1982. Aspectos taxonômicos das florestas do Estado de São Paulo. Silvicultura em São Paulo 16A:197-206. 
LEITÃO-FILHO, H.F., PAGANO, S.N., CESAR, O., TIMONI, J.L. \& RUEDA, J.J. 1993. Ecologia da Mata Atlântica em Cubatão (SP). EDUNESP/ EDUNICAMP, São Paulo.

MARTINS, S.V. \& RODRIGUES, R.R. 1999. Produção de serapilheira em clareiras de uma floresta estacional semidecídua no Município de Campinas, SP. Revista Brasileira de Botânica 22:405-412.

MEGURO, M., VINUEZA, G.N. \& DELITTI, B.C. 1979. Ciclagem de nutrientes minerais na Mata Mesófila secundária - São Paulo. I - Produção e conteúdo de nutrientes minerais no folhedo. Boletim de Botânica da Universidade de São Paulo 7:11-31.

MORAES, R.M., DELITTI, W.B.C. \& STRUFFALDI-DE VUONO, Y. 1999. Litterfall and litter nutrient content in two Brazilian Tropical Forests. Revista Brasileira de Botânica 22:9-16.
MORELLATO, L.P.C. 1992. Nutrient cycling in two south-east Brazilian forest. I - Litterfall and litter standing crop. Journal of Tropical Ecology 8:205-215.

PAGANO, S.N. 1989. Produção de folhedo em mata mesófila semidecídua no Município de Rio Claro, São Paulo. Revista Brasileira de Biologia 49:633-639.

SCHLITTLER, F.H.M., MARINIS, G. \& CÉSAR, O. 1993. Produção de serapilheira na floresta no Morro do Diabo, Pontal de Paranapanema, São Paulo. Naturalia 18:135-147.

SONGWE, N.C., FASEHUN, F.E. \& OKALI, D.U.U. 1988. Litterfall and productivity in a tropical rain forest, Southern Bankundu Forest, Cameroon. Journal of Tropical Ecology 4:25-37.

WERNECK, M.S., PEDRALLI, G., KOENIG, R. \& GIESEKE, L.F. 2000. Florística e estrutura de três trechos de uma floresta semidecídua na Estação Ecológica do Tripuí, Ouro Preto, MG. Revista Brasileira de Botânica 23:97-106.

ZAR, J.H. 1999. Biostatiscal analysis. Prentice-Hall, New Jersey. 